\title{
Current and developing therapeutic agents in the treatment of Chagas disease
}

\author{
This article was published in the following Dove Press journal: \\ Drug Design, Development and Therapy \\ 16 September 2010 \\ Number of times this article has been viewed
}

\author{
Werner Apt \\ University of Chile, Faculty \\ of Medicine, Santiago, Chile
}

Correspondence: Werner Apt Main Professor of Parasitology, Independencia 1027, Santiago, Chile

Tel $+5629786 / 22$

Fax +56 29786122

Email wapt@med.uchile.cl

\begin{abstract}
Chagas disease must be treated in all its stages: acute, indeterminate, chronic, and initial and middle determinant chronic, due to the fact that DNA of the parasite can be demonstrated by PCR in chronic cases, where optical microscopy does not detect parasites. Nifurtimox (NF) and benznidazole (BNZ) are the drugs accepted to treat humans based upon ethical considerations and efficiency. However, both the drugs produce secondary effects in $30 \%$ of the cases, and the treatment must be given for at least 30-60 days. Other useful drugs are itraconazole and posaconazole. The latter may be the drug to treat Chagas disease in the future when all the investigations related to it are finished. At present, there is no criterion of cure for chronic cases since in the majority, the serology remains positive, although it may decrease. In acute cases, $70 \%$ cure with $\mathrm{NF}$ and $75 \%$ with BNZ is achieved. In congenital cases, $100 \%$ cure is obtained if the treatment is performed during the first year of life. In chronic acquired cases, $20 \%$ cure and 50\% improvement of the electrocardiographic changes are obtained with itraconazole.
\end{abstract}

Keywords: Chagas disease, treatment, nifurtimox, benznidazole, allopurinol, itraconazole, posaconazole

\section{Introduction}

Recently, we have celebrated the centenary of the discovery of Chagas disease by the distinguished Brazilian investigator, Dr Carlos Chagas (1909-2009). ${ }^{1}$

Although we know that Chagas disease has existed for more than 9000 years by the demonstration of Trypanosoma cruzi in remains of mummies off the coast of southern Peru and northern Chile belonging to the Chinchorro culture (7000 BC to $1500 \mathrm{AD}){ }^{2}$ its etiological treatment is recent, dating from the decade 1970 to1980 when nifurtimox (NF) and benznidazole (BNZ) were applied based on an empirical therapy. ${ }^{3-5}$

There are several drugs which act in vitro on T. cruzi, in cultures of epimastigotes and trypomastigotes, in tissue cultures of amastigote forms, and in vivo in different species of infected animals with diverse strains (subpopulations) of the parasite. It is important to point out that the drugs which are used in Chagas disease therapy must have an effect on the intracellular amastigote forms, which are the reproductive forms in the vertebrate host. The epimastigote and trypomastigote forms of these hosts derive from the amastigotes, and for this reason, their response to different drugs has less importance. ${ }^{6,7}$

A rational therapy for $T$. cruzi should be based on the following:

1. Inhibitors of trypanothione metabolism

2. Inhibitors of cysteine protease

3. Inhibitors of phospholipids 
4. Inhibitors of pyrophosphate metabolism

5. Drugs which inhibit protein or purine synthesis

6. Inhibitors of ergosterol

7. Natural drugs

\section{Inhibitors of trypanothione metabolism}

Trypanothione ( $\mathrm{N}^{1}, \mathrm{~N}^{8}$-bisglutatyonilspermidine) and trypanothione reductase are unique systems in the kinetoplastid protozoa, which replace intracellular glutathione and glutathione reductase, the principal mechanism of the thyolredux system. Although trypanothione reductase is an essential enzyme in Leishmania donovani and Leishmania mayor, the overexpression of the enzyme in L. donovani and L. mayor does not alter its sensitivity in vitro to agents that induce oxidative stress such as NF, nitrofurazone, and gentian violet. Inhibitors of trypanothione metabolism such as buthionine sulfoximine (BSO) are ideal potential candidates as drugs against $T$. cruzi; alone or jointly with free radical-producing drugs such as NF and $\mathrm{BNZ}^{8}$ (Figure 1).

\section{Cysteine protease inhibitors (CPI)}

Cruzipain (cruzain, gp 51/57) is a simile of cathepsin L-cysteine protease responsible for the proteolytic activity in all the life stages of T. cruzi. The genes that code for this protein have been cloned and expressed. A recombinant enzyme has been elaborated, and different drugs have been studied which inhibit specifically the CPI protease in vitro, blocking the proliferation of epimastigotes and amastigotes and arresting metacyclogenesis. It has been demonstrated that these drugs block the development of cruzipain and its transport by lysosomes. These facts indicate that cruzipain is an ideal target; however, to date, although CPI has been applied in murine models with acute and chronic infection, obtaining parasitological cure with minimal toxicity, the short half-life of the drug, which requires high and increasing doses, inhibits its use in clinical practice. ${ }^{9}$

\section{Inhibitors of phospholipids}

Alkyl-lysophospholipids (ALP) are synthetic analogs of lysophospholipids, which have been shown to be effective in vitro and in vivo on $T$. cruzi and trypanosomatides. Miltefosine, one of its representatives, has been used orally in visceral leishmaniasis with good results. ALP selectively blocks the biosynthesis of phosphatydilcoline (PC) of T. cruzi through the transmethylation of the Greenberg pathway, in contrast to the vertebrate host where the Kennedy pathway of CDP choline is predominant. ${ }^{10}$ However, it is necessary to assess its clinical efficacy in Chagas disease because miltefosine is teratogenic, and congenital transmission of T. cruzi is actually a real problem.

\section{Inhibitors of pyrophosphate metabolism}

The inorganic pyrophosphates $\left(\mathrm{P}_{2} \mathrm{O}_{7}^{4-} ; \mathrm{PPi}\right)$ and other short chain, tri and tetra, polyphosphates are those which have the greatest energy of phosphate compounds in trypanosomatides (T. cruzi, Trypanosoma brucei, and Leishmania mexicana) and

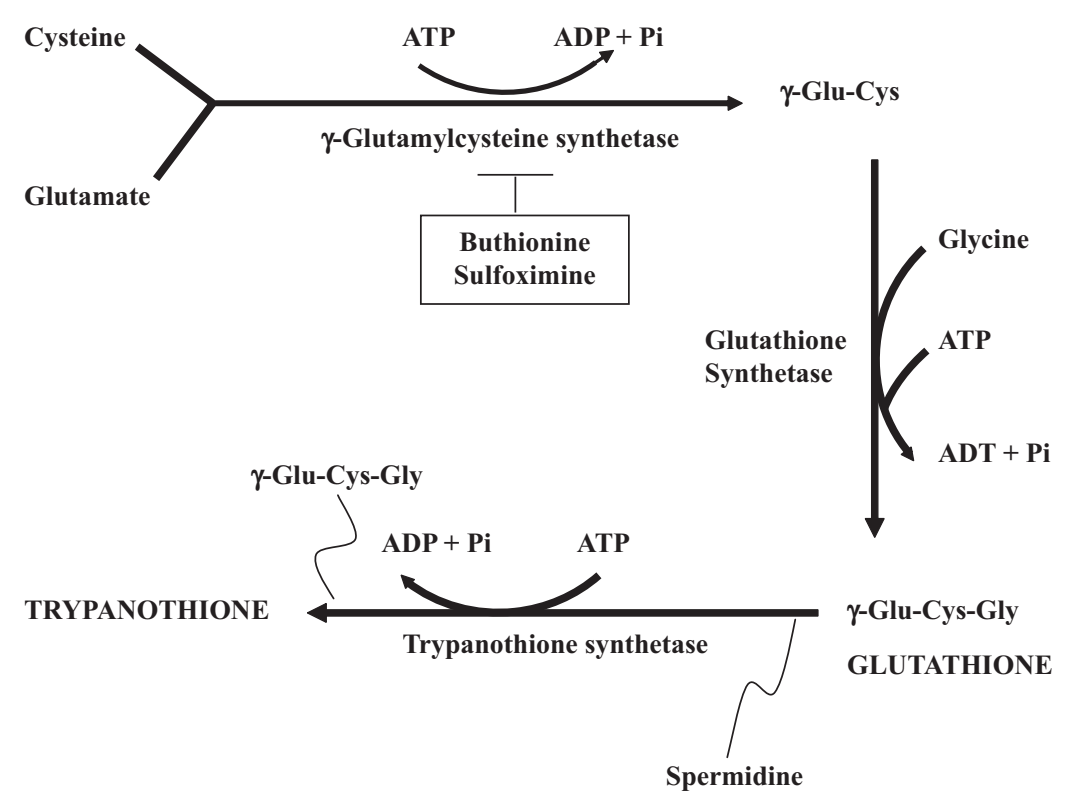

Figure I Biosynthesis of glutathione and trypanothione in T. cruzi: Glutathione is synthesized by the consecutive action of $\gamma$-glutamylcysteine synthetase and glutathione synthetase in an ATP-dependent reaction. In T. cruzi, two molecules of glutathione are conjugated with spermidine to synthesize trypanothione ( $\mathrm{N}^{\prime}$, $\mathrm{N}^{8}$-bisglutathionylspermidine, $\left.\mathrm{T}(\mathrm{SH})_{2}\right)$. The host is unable to synthesize $\mathrm{T}(\mathrm{SH})_{2} \cdot \gamma$-Glutamylcysteine synthetase is the step-limiting enzyme in this process and can be inhibited by BSO. 
apicomplexa parasites (Toxoplasma gondii). They have 10-15 times more energy than ATP. PPi is distributed throughout the cell but is concentrated in the acidocalcisomes, specialized acid vacuoles with large quantities of $\mathrm{Ca}^{++}$. PPi enzymes of $T$. cruzi, such as a proton-translocating pyrophosphatase in acidocalcisomes and pyruvate phosphate dikinase in glycosomes, suggest that PPi has an important role in parasite survival. This has been confirmed by the observation that pamidronate, alendronate, and risedronate, which contain biphosphonates, nonmetabolizable pyrophosphate analogs currently used in human medicine in alterations of bone reabsorption, selectively inhibit the proliferation of intracellular amastigotes and tachyzoites of $T$. gondii. It has been demonstrated that risedronate (Ris) acts in vitro on epimastigotes and cell cultures of amastigotes of $T$. cruzi and also reduces the infection in mice with acute infection, eliminating almost completely the parasitemia and intracellular amastigote forms. This drug inhibits the farnesyl pyrophosphate synthase of the parasite, blocking the biosynthesis of poly-isoprenoids. ${ }^{11}$ One inhibitor of farnesyltransferase, tipifarnib (R 115777), which inhibits cytochrome $\mathrm{P} 450$ sterol demethylase $\left(\mathrm{CYP}_{51}\right)$, is a potential target against $T$. cruzi, but in spite of its success in experimental animals, it has not been applied in humans. ${ }^{12}$

The sterol 14 demethylase of T. cruzi has been studied (TCCYP51). It is related catalytically to the CYP51 of animal fungi. ${ }^{13}$ Inhibition by obtusifoliol and its analogs reduce enzyme activity enormously. TCCYP51 constitutes a potential target against $T$. cruzi; however, to date, no experimental surveys had been performed to establish its efficacy in animals.

Most of the inhibitors of pyrophosphate metabolism, which contain bisphosphonates, are associated to long-term bone necrosis. These serious side effects in humans discard them as potential candidates for therapy.

\section{Drugs which inhibit protein or purine synthesis}

Allopurinol

T. cruzi cannot synthesize purines de novo as humans do. Allopurinol, 4-hydroxypirazole(3,4-d)pyrimidine (HPP), is an analog of hypoxanthine, which decreases uric acid and the conversion of hypoxanthine to xanthine. For this reason, it is used to treat gout, which is characterized by the deposit of uric acid in the joints. HPP inhibits the epimastigote forms in culture. In mice infected with $T$. cruzi and treated with allopurinol, an important reduction of the parasitemia is obtained, although some parasite strains are resistant to the drug. ${ }^{14}$ T. cruzi changes HPP to APP (4 aminopyrazolo(3,4-d) pyrimidine), which is 15 times more powerful against epimastigotes than HPP. If APP is administered to mice infected with $T$. cruzi, a suppression of the parasitemia is obtained with a dose 400 times lower than allopurinol. ${ }^{15}$ In patients with acute Chagas disease treated with allopurinol at high doses (20-30 mg/day) for 60 days, no reduction of the parasite burden was obtained. In a multinational study performed in Argentina, Brazil, and Bolivia in patients with chronic Chagas disease treated with $900 \mathrm{mg}$ /day for 60 days, no parasitological cure was obtained. This drug was well tolerated in a number of studies performed in patients with chronic Chagas disease, and in some of these, an improvement of the electrocardiographic alterations in chronic Chagas cardiopathy (CCC) was demonstrated. ${ }^{16,17}$ It has been used in heart transplants in Chagas patients with good results. ${ }^{18}$ In exceptional cases, it has been necessary to suspend the treatment due to its secondary effects. ${ }^{17}$

\section{Inhibitors of ergosterol}

Diverse azolic products have been used with success in human and veterinary medicine. These drugs interface in sterol synthesis and, together with other heterocyclic nitrogenated compounds, belong to the group of drugs which inhibit ergosterol synthesis. T. cruzi has ergosterol; the antimycotic prevents its synthesis without affecting the human host, who has cholesterol. Cholesterol differs from ergosterol by the presence of a 24 methyl group and double bonds in 7A and 22A. The enzymes which produce the methylation and the double bonds of ergosterol do not have counterparts in mammalian cholesterol synthesis. Several of these azolic products have been studied for Chagas disease treatment: miconazole, econazole, ketoconazole, itraconazole, fluconazole, and posaconazole (Figure 2). With these drugs, a parasitological cure has been obtained in mice with acute and chronic Chagas disease. ${ }^{19}$ Ketoconazole, itraconazole, and DO 870 inhibit cytochrome P450-dependent lanosterol C14 demethylase, thus reducing ergosterol synthesis. Although mammals have this enzyme, it is much less sensitive to the drugs than those of fungi or of $T$. cruzi. Itraconazole has been applied in the treatment of chronic indeterminate Chagas disease and CCC, based on the results of the drug in experimental investigations. ${ }^{20}$

The absolute oral bioavailability of itraconazole was 55\% after a single 100-mg capsule was taken by six volunteers. The bioavailability was maximal when the capsules were taken with a full meal.

The drug prevents cardiopathy, compared to controls without therapy, and improves $50 \%$ of the electrocardiographic alterations of patients with CCC. Twenty percent of these cases are 'cured' of parasites, determined by xenodiagnosis, PCR in 


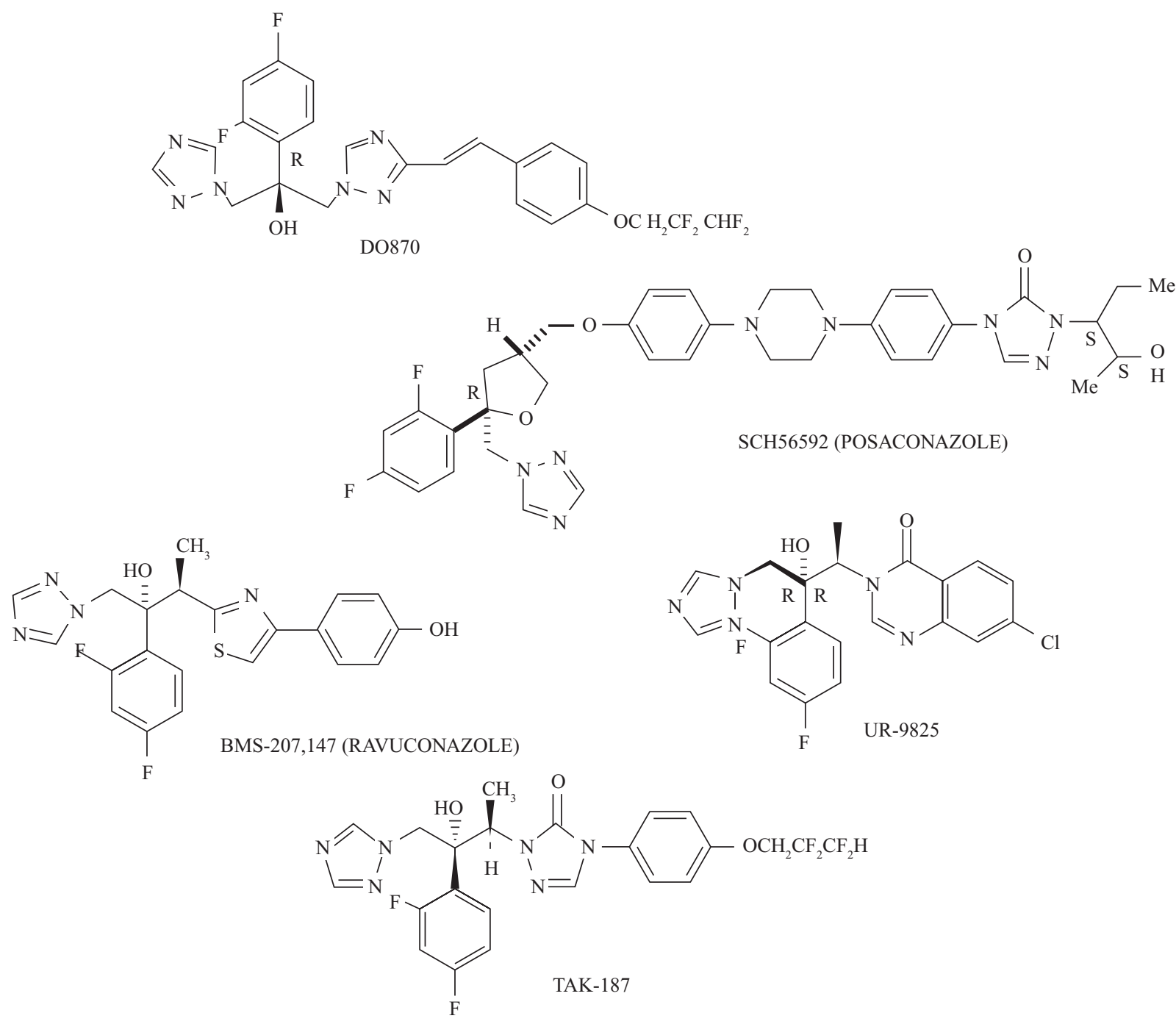

Figure 2 Chemical structure of triazole derivatives, inhibitors of $T$. cruzi sterol $\mathrm{Cl} 4 \alpha$ sterol demethylase.

blood, hybridization probes in blood, PCR in dejections, and hybridization probes in dejections of triatomines applied to these patients. ${ }^{21}$ However, none of the 'cured' cases presented a negative conventional serology (indirect hemagglutination (IHA), indirect immunofluorescence (IF), or ELISA) for $T$. cruzi. ${ }^{17}$ When the drug DO 870 was administered to mice with acute infection $\left(10^{5}\right.$ T. cruzi $Y$ strain $)$, the treated animals lived longer than the controls without treatment or those treated with NF or ketoconazole; 105 days survival versus 21 . A $60 \%$ cure was obtained, which was judged by control of parasitemia, hemocultures, and PCR. When this therapy was applied to mice with chronic infection $\left(10^{4}\right.$ T. cruzi Bertoldo strain), after $40-50$ days, $50 \%$ of the controls survived and $30 \%$ of these had negative PCR, whereas the parasitological cure was $80 \%-90 \%$ in the treated group. ${ }^{19}$ Today, DO 870 has been discontinued because of its cardiotoxicity, but posaconazole (SCH 56592), BMS-207, 147 (ravucon- azole), VR-9825, and TAK-187 have demonstrated activity against $T$. cruzi in vitro and in vivo. Of these compounds, posaconazole has proved to be efficient and with very good tolerance in studies performed in patients with oropharyngeal candidiasis. ${ }^{22}$ It has been observed that the majority of these compounds (posaconazole, ravuconazole, VR-9825, and TAK-187) have activity against $T$. cruzi strains partially resistant to NF, BNZ, and in which ketaconazole does not function. ${ }^{10}$ Posaconazol with amiodarona, an antiarrhythmic drug, has a synergistic activity against $T$. cruzi in vitro and in vivo. ${ }^{23}$ Recently, success was demonstrated with posaconazole in a patient with chronic Chagas disease and systemic lupus erythematosus. This patient was previously treated with BNZ with reduction of the parasitemia but not elimination of T. cruzi. ${ }^{24}$ Posaconazole maximal absorption, $T_{\max }$, is approximately $3-5 \mathrm{~h}$. Steady-state plasma concentrations are reached in $7-10$ days. $V_{\mathrm{d}}$ is $1774 \mathrm{~L}$, suggesting extensive extravascular 
distribution and penetration into body tissues. Over $98 \%$ of the drug is bound, protein primary to albumin.

Its metabolism involves glucuronide conjugation via uridine diphosphate glucuronidation. Its elimination is approximately $71 \%$ in feces and $13 \%$ in urine in up to $120 \mathrm{~h}$. The mean $t_{1 / 2}$ is $35 \mathrm{~h}$.

\section{Natural drugs}

A great spectrum natural of products has been used against T. cruzi, but very few are useful at a concentration of $10 \mu \mathrm{g} / \mathrm{mL}$, considering that the $\mathrm{IC}_{50}$ for $\mathrm{NF}$ and $\mathrm{BNZ}$ is less than $3 \mu \mathrm{g} / \mathrm{mL}$. Some products block the respiratory chain of the parasite, such as boldo (Peumus boldus) alkaloids and naphthoquinone extracted from Calceolaria sessilis. ${ }^{25}$ Other alkaloids extracted from Brazilian plants which have isoquinoline have an effect on $T$. cruzi. ${ }^{26}$ Some natural drugs inhibit the response of $T$. cruzi to oxidative stress by producing superoxide radicals. ${ }^{8}$ The triterpenes of Arrabidaea triplinervia and their derivatives, such as diterpenes, komaroviquinone, and terpenoids isolated from Pinus oocarpa, have action on epimastigotes and trypomastigotes of $T$. cruzi. $^{27-29}$ In the majority of the natural drugs, the exact mechanism of action is not known. The great majority of them have effects on epimastigote forms and some on culture amastigotes. Very few have been used in experimental studies in murines, and none have been used in clinical surveys. To date, no natural product which acts on T. cruzi transialidase has been studied, although this enzyme is an optimal target. Only one natural drug has been used on CPI, inhibiting cruzipain synthesis; this product is a 164-residue amino acid protein extracted from seeds of Bauhinia bauhinioides. No experimental investigations have been performed with this product. ${ }^{30}$

\section{Treatment of human infection}

Chagas disease has regional characteristics. In Brazil, achalasia of the esophagus is more frequent than megacolon, whereas in Chile, it is the opposite. Acute acquired clinical cases are frequent in the Chaco region of Argentina, Paraguay, and Bolivia but are infrequent in Chile. ${ }^{31}$

Treatment with NF and BNZ began in the 1970s and is based on an empirical treatment. ${ }^{32-34} \mathrm{NF}$ is 4-([5nitrofurfuryledene]amino)-3-methylthiomorpholine-1,1 dioxide (Figure 3 ). It acts by the production of free radicals, superoxide anions, hydrogen peroxide, and electrophilic metabolites. ${ }^{35}$ It has been demonstrated that in addition to the metabolic action of the drug on T. cruzi, its incorporation and transport by the parasite is of great importance. There are strains with some resistance to NF, which differ due to a

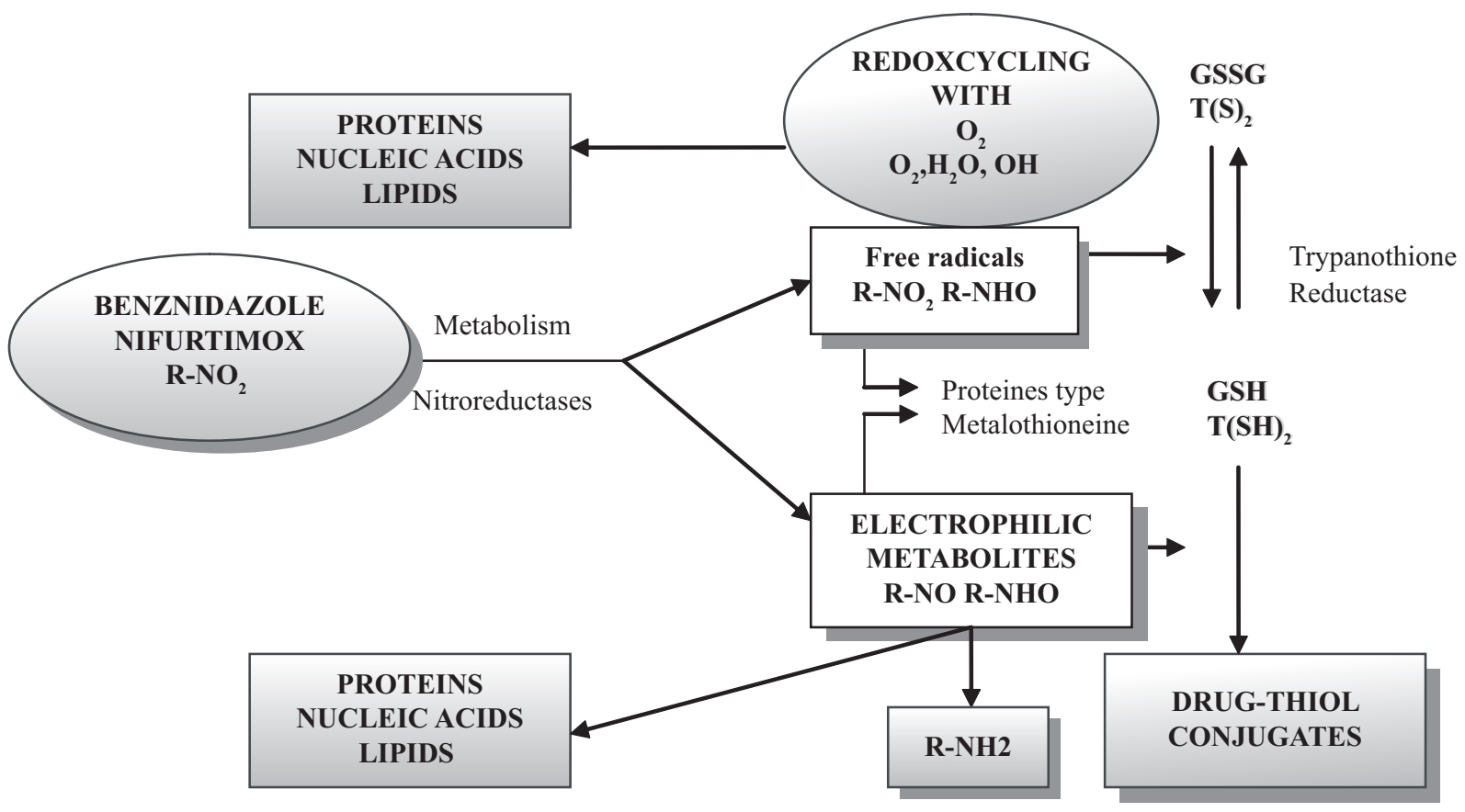

Figure 3 Role of glutathione and trypanothione in the action and metabolism of the anti-Chagasic drugs nifurtimox and benznidazole. The nitro group of both anti-Chagasic drugs is reduced to free radicals or electrophilic metabolites by $T$. cruzi cytochrome P450-related nitroreductases. The nifurtimox-derived free radicals may undergo redox cycling with oxygen, and $\mathrm{H}_{2} \mathrm{O}_{2}$ is produced by the further action of superoxide dismutase (SOD). The produced oxygen-derived free radicals and electrophilic metabolites bind to intracellular macromolecules, damaging them. In the parasite, trypanothione $\left(\mathrm{T}(\mathrm{SH})_{2}\right)$ and glutathione (GSH) neutralize the nifurtimox- and benznidazole-derived metabolites by conjugation, producing drug-thiol conjugates that will be further metabolized to mercapturates in the mammal host. Free radicals are neutralized, and there is oxidation of reduced $\mathrm{GSH}$ or $\mathrm{T}(\mathrm{SH})_{2}$. Trypanothione reductase reduces oxidized trypanothione $\left(\mathrm{T}(\mathrm{S})_{2}\right)$. 
lower intake and transportation of the drug, rather than by the amount of free radical production. T. cruzi, in the presence of NF, increases oxygen consumption and $\mathrm{H}_{2} \mathrm{O}_{2}$ and superoxide radical production.

The drug BNZ (N-benzyl-2-nitroimidazole-1-acetamide) was introduced for human clinical use in 1978. The drug inhibits protein synthesis, originating a degradation of macromolecule biosynthesis. Reduced metabolites of BNZ in covalent unions with macromolecules interact with the DNA of the parasite. ${ }^{8}$ The drug inhibits the respiratory chain. The free radical production is lower than with NF. Figure 3 describes the mechanisms of action of NF and BNZ. Both drugs produce important collateral effects, especially in adults, because newborn, nursing, and small children tolerate the drugs better. ${ }^{36}$ The secondary effects of NF and BNZ are described in Table 1. Based on this information, we will discuss the treatment of human Chagas disease in its different stages with the drugs currently in use.

\section{Current drug therapy}

Some investigators believe that Chagas disease must be treated only in acute (acquired or congenital) or chronic reactivated cases (by immunosuppression diseases like AIDS; other immune depression diseases, iatrogenic immune depression, like transplants, etc). They do not agree to treat chronic indeterminate or determinate cases based on the fact that the pathology is originated by an autoimmune process. ${ }^{37-40}$ Nevertheless, the other group of scientific investigators believe that the treatment of chronic Chagas disease is important, based on the observation of DNA of T. cruzi by PCR in cases where optical and election microscopy do not. ${ }^{41,42}$ It is difficult to sustain that this

Table I Adverse reactions to nifurtimox and benznidazole

\begin{tabular}{l} 
Digestive alterations \\
Loss of weight \\
Gastric upset \\
Nausea \\
Vomiting \\
Hematological alterations (by hypersensitivity) \\
Leukopenia \\
Thrombocytopenia \\
Agranulocytosis \\
Dermatological alterations \\
Erythematous, light-sensitive rash \\
Atopic dermatitis (mild or severe) \\
Occasionally, Stevens-Johnson syndrome, which requires the suspension \\
of therapy \\
Neurological alterations \\
Polyneuropathy, dose dependent. In general, it appears in schedules of \\
high dose. In the usual dose of $5 \mathrm{mg} / \mathrm{kg} /$ day of benznidazole, I0\%-30\% of \\
the patients present neuropathies, especially at the end of treatment. \\
\hline
\end{tabular}

finding corresponds to DNA of death parasites because it has been detected in many cases with several decades of evolution. ${ }^{42,43}$ It has been demonstrated that there is a correlation between the antigen burden and/or DNA of the parasite with the intensity of the pathological processes (inflammation, cellular damage) in experimental animal surveys and in humans with chronic infection. ${ }^{44-46}$ There are no investigations which directly demonstrate the vitality of the parasites in chronic Chagasic patients, but there are investigations that indicate the utility of the treatment. ${ }^{47-53}$

Furthermore, OPS-WHO and a group of experts on Chagas disease patronize treatment in acute and initial middle chronic cases. ${ }^{54}$ To determinate the utility of BNZ in the treatment of CCC, a multinational survey is been performed, the Benefit Project. In a pilot survey double-blind of 600 cases, $300 \mathrm{CCC}$ received BNZ $5 \mathrm{mg} / \mathrm{kg}$ during 60 days and 300 placebo. The second group included 6000 patients, 3000 with BNZ and 3000 with placebo. It is expected that in 2012-2013, the investigation will be finished. ${ }^{55,56}$ Recently, it has been demonstrated that in patients with CCC, the antibodies against $T$. cruzi only react with antigens of the parasite and not with the antigens from the host. ${ }^{57}$ These investigations and others which demonstrate that there is no correlation between the intensity of the autoimmune processes (when they appear) and the magnitude of the damage in chronic Chagas disease ${ }^{43}$ are against the autoimmune theory.

\section{Acute cases}

Patients with clinical manifestations must receive treatment: those with an infection of less than 4 months, as well as the acute cases with easy detection of parasites in fresh samples and smears and with positive conventional serology (IHA, complement fixation (CF), IF, ELISA, and immunoblotting (IB) with positive IgM). The ideal is to treat these cases with $\mathrm{NF} 8 \mathrm{mg} / \mathrm{kg}$ /day for 30-60 days in adults and $10 \mathrm{mg} / \mathrm{kg} /$ day for the same period in children. This daily quantity must be divided into three doses taken after meals (every $8 \mathrm{~h}$ ). In Brazil, where NF does not exist, BNZ is used: $5 \mathrm{mg} / \mathrm{kg} /$ day for 60 days in adults and 5-10 mg/ $\mathrm{kg} /$ day $(7.5 \mathrm{mg} / \mathrm{kg} /$ day $)$ for 60 days in children divided into two or three doses (every 12 or $8 \mathrm{~h}$ ) after meals. In an investigation performed in Santiago del Estero (Argentina) with 470 cases, the majority of the children (84.4\%) aged 1-9 years with acute Chagas disease who presented an ophthalmic lymph node complex, 367 were treated with $25 \mathrm{mg} / \mathrm{kg}$ of NF for 15 days continuing with $15 \mathrm{mg} / \mathrm{kg}$ for another 77 days, whereas 40 received placebo and another 20 other anti-Chagasic drugs. The drug tolerance was greater in small children, and the dose of $15 \mathrm{mg}$ was bet- 
ter tolerated than that of $25 \mathrm{mg}$. After 60 days of treatment, the direct parasitological tests were negative in both the groups who received therapy; however, in the placebo group, there were $28.6 \%$ positive cases. After 18 months, there was $69 \%$ seroconversion of the treated patients; in other words, they passed from positive to negative. However, the placebo group maintained positive serology, IHA, CF, and IF. ${ }^{58}$ With BNZ in acute acquired cases, $76 \%$ cure is obtained. ${ }^{59}$

\section{Congenital infection}

Treatment must commence as soon as the diagnosis is performed, in other words, when the clinical suspicion is confirmed by observation of the parasite in fresh samples of blood smears, microstrout, etc. Sometimes the diagnosis is confirmed when the child is in the chronic period ( 8 or more months) by persistent positive serology after this period. Better therapeutic results are obtained when the diagnosis is more precocious. It is important to perform a clinical, serological, and parasitological follow-up of the treated newborn. Recently, the utility of PCR in the precocious diagnosis of congenital Chagas disease in neonates has been confirmed; its effectiveness is greater than that of xenodiagnosis. ${ }^{60,61}$ This technique has great utility as has been demonstrated by Paraguayan investigators and others in the follow-up of treated cases. Thus, for example, in an investigation performed in the maternity ward of the Clinical Hospital of Asunción and in the Regional Hospital of San Pedro, Paraguay, the newborn of Chagasic mothers were studied. Three percent were positive by microscopy, which increased to $10 \%$ when they added the cases with persistent positive serology at 6 months. Out of 58 newborn, in two cases, T. cruzi was observed at birth and four presented positive PCR with negative microscopic investigation. All the positive cases were treated with BNZ and followed for four years by conventional serology and PCR. In another study performed in an endemic area of Paraguay of 1865 neonates with Chagasic mothers, in 104 cases, congenital infection was demonstrated by direct microscopic observation, PCR, and serology; ELISA, ELISA AIDS, and IF. PCR was the most sensitive test. ${ }^{62}$

All congenital cases must be treated since up to $98 \%$ of such treatments may produce negative serology and parasitemia; the earlier the treatment is begun, the better the response obtained. NF must be administered in doses of $8-10 \mathrm{mg} / \mathrm{kg} /$ day for 60 days, taken every 8 or $12 \mathrm{~h}$, or BNZ 5-7 mg/kg/day for 60 days. To avoid secondary effects (convulsions), it is recommended to associate phenobarbital in therapeutic doses during the first 15 days of treatment. In case of secondary dermatological reactions, it is suggested to add antihistaminics. Adverse reactions in neonates are fewer than in adults.

It is important to perform a precocious diagnosis of congenital cases to treat them opportunely. For this purpose, the following is suggested in pregnant women and newborn.

\section{Pregnant women}

Serological test jointly with other tests such as VDRL during the first trimester of pregnancy and follow-up of the positive cases, until the diagnosis of congenital infection is confirmed or discarded. This activity must be performed in all women of fertile age, in pregnant women from endemic areas, and in women with a history of having lived in these zones.

\section{Newborn}

Serological study for T. cruzi infection, together with VDRL and other tests. In the positive cases, a follow-up must be realized until the diagnosis is confirmed or discarded.

\section{Accidental Chagas disease}

All accidental cases must be treated with the same drugs as the acute infections acquired from the vector for 15 days. In this group, the transfusion by error from a Chagasic donor must be considered. In persons who work in laboratories and have a puncture accident with contaminated samples with infective $T$. cruzi forms, the confirmation of the contamination of the object with the parasite and the posterior infection of the patient (serology and PCR) must be performed. If there are positive results, immediate treatment must be undertaken with BNZ 7-10 mg/kg/day for 15 days, depending on the immunological state of the person. A serological study must be done at 15-30 and 60 days.

\section{Organ transplants}

A transplant in which the donor or recipient has Chagas disease must always be treated, with NF $8 \mathrm{mg} / \mathrm{kg} /$ day in adults, $10 \mathrm{mg} / \mathrm{kg} /$ day in children for 60 days, or BNZ $5 \mathrm{mg} / \mathrm{kg} /$ day in adults and $5-8 \mathrm{mg} / \mathrm{kg} /$ day in children for 60 days. In bone marrow transplants with $T$. cruzi infections (which receive it in $40 \%$ of the cases), the treatment must be maintained for 2 years, and in solid organ receptors, treatment must be given for the period in which immunosuppressors with insufficient CD4 lymphocytes for an adequate immune response are used. In these patients, the most commonly prescribed drugs are the traditional NF and BNZ. In the model of patients exposed by organ transplant, a number of situations may be produced, such as primoinfections and reactivations; thus, it is important 
to perform a good screening of donor and recipient before the transplant. The clinical manifestations of reactivation usually differ from that of the acute phase (primoinfection); for this reason, the monitoring of patients after the transplant is relevant. In both situations, the receptor who receives an organ from a Chagasic donor or a Chagasic reactivated receptor must be treated with NF or BNZ.

\section{Reactivations of chronic Chagas disease and treatment of Chagas disease in immunosuppressed patients}

Patients with chronic Chagas disease who acquire AIDS or in whom immunosuppressor therapy is administered must receive treatment at the same dose as the group mentioned above for 5 or more months. In these cases, the most suitable strategy is prevention, performing serology for Chagas disease in all AIDS patients. In the primoinfection by $T$. cruzi in AIDS patients, the same treatment schedule must be prescribed as in reactivations, in other words, the same classic antiparasitic drugs are used in the standard doses until the immune response of the host is reconstituted (in some cases 60 or more days). Once the alteration of the immune system is normalized, including the relation $\mathrm{CD} 4 / \mathrm{CD} 8$, the antiparasitic schedule is changed to every 3 days, balancing the parasiticide effects with the adverse effects. AIDS patients without retroviral treatment are the most severely affected. In them, once the CD4 levels are normalized with specific antiviral treatment, maintenance schedules may be used.

\section{Evaluation and follow-up of specific therapy}

The principal objection to the treatment of Chagas disease is its long duration. The treatment must be maintained at least for 60 days, and the cure criteria depend on several factors. ${ }^{63,51}$ Some authors consider serological conversion as necessary, but this sometimes happens 20 years or more after the end of treatment of chronic Chagas disease, and there are cases in which former patients die without seroconversion. Recently, it has been published that in treated cured mice experimentally infected with $T$. cruzi, in which no parasites and no T. cruzi antigens could be demonstrated, CD8 central memory cells maintain a positive serology for more than a year. ${ }^{64}$ We do not know if this process occurs in man, but if it does, we could explain why a cure in chronic cases may be reached without seroconversion.
Others consider the following parameters as cure criteria of the chronic period: the conversion of the xenodiagnosis from positive to negative, conversion of qualitative PCR from positive to negative, and in cardiopathies, the elimination of the electrocardiographic alterations. These changes must always be permanent and must persist for at least 12 or more years independently of the conventional serological results. There must be at least two parasitological and one or more clinical parameters to confirm the cure. ${ }^{17}$ In the acute indeterminate and determinate chronic periods, a follow-up must be performed with hemocultures, quantitative PCR for T. cruzi, hemogram, biochemical profile, and/or xenodiagnosis. ${ }^{65,66}$ It must be kept in mind that serological tests in severe immunosuppressed patients usually have negative results and for this reason don't serve to follow up the treatment. A prolonged persistent negativity of PCR with the mentioned characteristics for T. cruzi is considered as a cure criterion. Some authors give value to the disappearance of lytic antibodies as a complement to improve the criterion.

\section{Resistance of T. cruzi to drugs}

In vitro and in vivo

It has been demonstrated that certain T. cruzi strains are resistant to NF and BNZ. This is valid especially for $T$. cruzi clones isolated from wild animals or vectors. It is important to emphasize that we do not know if what we observe in murine models happens in man. Furthermore, in many publications, the strains of $T$. cruzi have not been well characterized by isozymes (zymodemes), nuclear restriction enzymes (schizodemes), genetic composition, etc. ${ }^{67}$ No consensus exists on the relation of the sensitive or resistant strains and virulence. ${ }^{68}$ Some investigators have claimed that there is a relation, in other words, the resistant strains are more virulent, while others did not find this association. ${ }^{69}$ In relation to the genetic composition of T. cruzi and resistance to drugs, it has been demonstrated in vitro that a relation exists between genetic distances and biological differences; among the latter, the resistance to NF and BNZ. This is true for epimastigotes and amastigotes. Trypomastigotes are the exception since in them, a relation between genetic distance and sensitivity to drugs does not exist. It is necessary to have better genotypic studies of T. cruzi in relation to resistance to drugs. Recently, it has been demonstrated that patients with chronic Chagas disease treated with itraconazole or allopurinol who did not respond to the specific therapy (there was no parasitological cure) were infected with the TCI lineage of T. cruzi, whereas those who responded to the therapy with itraconazole had 
the lineage TCIIb, suggesting that TCI is resistant to these drugs and TCIIb is sensitive. ${ }^{70}$

\section{Critical comments}

At present, there is no effective therapy for the majority of the patients who have chronic Chagas disease in the indeterminate $(70 \%-80 \%)$ and determinate $(10 \%-20 \%)$ periods. In the acquired acute period, $70 \%$ of the cases are cured, and in newborn and nursing children with congenital Chagas disease, $98 \%-100 \%$ cure is obtained. In the chronic acquired cases, cures reach $20 \%$ and improvement of cardiopathy $50 \%$ (with itraconazole). New drugs are needed with high efficacy and without secondary effects, especially to treat chronic cases. In the last few years, only posaconazole has been developed against human T. cruzi infection. This is due to the lack of interest of the international drug companies to develop new drugs with low returns. The people with Chagas disease have low economic resources. Chagas disease is one of 'neglected diseases,' and for this reason, the pharmaceutical companies do not show much interest. How will chronic Chagasic patients be treated if no new drugs are produced? They may have to be treated with itraconazole or posaconazole until better drugs are found.

\section{Future investigations}

In the near future, we believe that the etiological treatment of Chagas disease will include combination of drugs to obtain more efficiency and less secondary effects, eg, NF and BSO. Experimental studies in vitro and in vivo have demonstrated the synergism of these two drugs. ${ }^{8}$ Human investigations are needed to confirm these results. The same results could be expected with the association of BNZ and allopurinol or BNZ and posaconazole.

Other investigations with inhibitors of methylcarboxipeptidases of T. cruzi (an enzyme which doesn't exist in humans) are needed because its use could represent an effective therapy against Chagas disease.

\section{Acknowledgments}

We gratefully acknowledge the design of Figures 1 and 3 by Dr Diego Maya. This work was supported by FONDECYT grants 1080445 and 1100768 .

\section{Disclosure}

The author reports no conflicts of interest in this work.

\section{References}

1. Apt W. Centenario del descubrimiento de Carlos Chagas (1909-2009). Rev Parasitol Ibero-Latinoam. 2009;68:92-94.

2. Aufderheide A, Salo W, Madden M, et al. A 9000-year record of Chagas disease. Proc Natl Acad Sci U SA. 2004;101:2034-2039.
3. Pinto Dias J. Tratamiento etiológico de la enfermedad de Chagas. En XII Reunión de la Comisión Intergubernamental del Cono Sur para la eliminación de Triatoma infestans y la interrupción de la transmisión transfusional de la Tripanosomiasis Americana (INCOST/ Chagas). Washington, DC: Pan American Health Organization; 2004: 129-134.

4. Coura R. Chagas disease: clinical and therapeutic features. Enferm Emerg. 2005;8:18-24.

5. Steverding D, Tyler K. Novel antitrypanosomal agents. Expert Opin Investig Drugs. 2005;14:939-955.

6. Andrade Z, Andrade S. Patología Da Doença de Chagas. In Brener Z, Andrade Z, Barral-Neto M, editors. En Trypanosoma cruzi e doença de Chagas 2da. Edición. Río de Janeiro, Brazil: Guanabara Koogan; 2000:201-230.

7. Teixeira A, Nascimento R, Sturn N. Evolution and pathology in Chagas disease - a review. Mem Inst Oswaldo Cruz. 2006;101:463-491.

8. Faundez M, Pino L, Letelier P, et al. Buthionine sulfoximine increases the toxicity of nifurtimox and benznidazole to Trypanosoma cruzi. Antimicrob Agents Chemother. 2005;49:126-130.

9. Cazzulo J. Proteinases of Trypanosoma cruzi: potential targets for the chemotherapy of Chagas disease. Curr Top Med Chem. 2002;2: $1261-1271$.

10. Urbina J. New chemotherapeutic approaches for the treatment of Chagas disease (American Trypanosomiasis). Expert Opin Ther Pat. 2003;13: 661-669.

11. Garzoni L, Waghabi M, Baptista M, et al. Antiparasitic activity of risedronate in a murine model of acute Chagas disease. Int J Antimicrob Agents. 2004;23:286-290.

12. Hucke $\mathrm{O}$, Gelb M, Verlinde C, et al. The protein farnesyltransferase inhibitor Tipifarnib as a new lead for the development of drugs against Chagas disease. J Med Chem. 2005;48:5415-5418.

13. Lepesheva G, Zaitseva N, Nes W, et al. CYP51 from Trypanosoma cruzi: a phyla-specific residue in the $\mathrm{B}^{\prime}$ helix defines substrate preferences of sterol 14 alpha-demethylase. J Biol Chem. 2006;281: 3577-3585.

14. Avila J, Avila A. Trypanosoma cruzi allopurinol in the treatment of mice with experimental acute Chagas disease. Exp Parasitol. 1981;51: 204-208.

15. Avila J, Avila A, Muñoz E, et al. Trypanosoma cruzi: 4-aminopyrazolopyrimidine in the treatment of experimental Chagas disease. Exp Parasitol. 1983;56:236-240.

16. Apt W, Aguilera X, Arribada A, et al. Treatment of chronic Chagas disease with itraconazole and allopurinol. Am J Trop Med and Hyg. 1998;59:133-138.

17. Apt W, Arribada A, Zulantay I, et al. Itraconazole an Allopurinol in the treatment of chronic American tripanosomiasis: the results of clinical and parasitological examinations 11 years post treatment. Ann Trop Med Parasitol. 2005;99:733-741.

18. Tomimori-Yamashita J, Deps P, Almeida D, et al. Cutaneous manifestation of Chagas disease after heart transplantation: successful treatment with allopurinol. Br J Dermatol. 1997;4:626-630.

19. Urbina J. Chemotherapy of Chagas disease. Curr Pharm Des. 2002;8:287-295.

20. McCabe E, Remington J, Aranjo F. In vitro and in vivo effect of itraconazole against Trypanosoma cruzi. Am J Trop Med Hyg. 1986;35: 280-284.

21. Zulantay I, Apt W, Gil LC, et al. The PCR-based detection of Trypanosoma cruzi in the faeces of Triatoma infestans fed on patients with chronic American trypanosomiasis gives higher sensitivity and a quicker result than routine xenodiagnosis. Ann Trop Med Parasitol. 2007;101:673-679.

22. Skies D, Vazquez J, Anstead G, et al. Posaconazole for the treatment of azole-refractory oropharyngeal and esophageal candidiasis in subjects with HIV infection. Clin Infect Dis. 2007;44:607-614.

23. Benaim G, Sanders JM, Garcia-Marchán Y, et al. Amiodarone has intrinsic anti-Trypanosoma cruzi activity and acts synergistically with posaconazole. J Med Chem. 2009;49:892-999. 
24. Pinazo M, Espinosa G, Gállego M. Successful treatment with posaconazole of a patient with chronic Chagas disease and systemic lupus erythematosus. Am J Trop Med Hyg. 2010;82:583-587.

25. Morello A, Lipchenca I, Cassels B, et al. Trypanocidad effect of boldine and related alkaloids up on several strains of Trypanosoma cruzi. Comp Biochem Physiol. 1994;90:1-12.

26. Tempone A, Borborema S, de Andrade H Jr, et al. Antiprotozoal activity of Brazilian plant extracts from isoquinoline alkaloid-producing families. Phytomedicine. 2005;12:382-390.

27. Rubio J, Calderon J, Flores A, et al. Trypanocidad activity of oleoresin and terpenoids isolated from Pinus oocarpa. Naturforsch. 2005;60: $711-716$.

28. Uchiyama N, Kabututu Z, Kubata B, et al. Antichagasic activity of komaroviquinone is due to generation of reactive oxygen species catalyzed by Trypanosoma cruzi old yellow enzyme. Antimicrob Agents Chemother. 2005;49:5123-5126.

29. Leite J, Oliveira A, Lombardi J, et al. Trypanocidad activity of triterpenes from Arrabidaea triplinervia and derivatives. Biol Pharm Bull. 2006;29:2307-2309.

30. de Oliveira C, Santana L, Carmona A, et al. Structure of cruzipain/ cruzain inhibitors isolated from Bauhinia bauhinioides seeds. Biol Chem. 2001;382:847-852.

31. Apt W, Heitman I, Jercic MI, et al. Guía clínicas para la enfermedad de Chagas. Parte II Enfermedad de Chagas en el adulto. Parte IV Tratamiento. Rev Chilena Infectol. 2008;25:194-199 and 379-389.

32. Rassi A, Rassi A Jr, Rassi S. Cardiopatía crónica: arritmias. In Pinto Dias J, Coura J, editors. Doença de Chagas. Um manual para o clinico general. Río de Janeiro, Brazil: Fio Cruz; 1997:201-222.

33. Prata A. Abordagem general do paciente chagasico. In Pinto Dias J, Coura, editors. Clinica e terapeutica do doença de Chagas. Um manual práctico para o clinico general. Río de Janeiro: Fio Cruz; 1997: 115-126.

34. Pinto Dias J. The treatment of Chagas Disease (South American tripanosomiasis). Ann Int Med. 2006;144:772-774.

35. Maya J, Cassels B, Iturriaga-Vasquez P, et al. Mode of action of natural and synthetic drugs against Trypanosoma cruzi and their interaction with the mammalian host. Comp Biochem Physiol A Mol Integr Physiol. 2006;146:601-620.

36. Viotti R, Vigliano C, Lococo B, et al. Side effects of benznidazole as treatment of Chagas disease: fears and realities. Expert Rev Anti Infect Ther. 2009; 7:157-163.

37. Acosta A, Santos-Buch C. Autoimmune myocarditis induced by Trypanosoma cruzi. Lab Invest. 1985;71:1255-1261.

38. Kierszenbaum F. Chagas disease and the autoimmunity hypothesis. Clin Microbiol Rev. 1999;12:210-223.

39. Andrade S, Pimentel A, de Souza M, et al. Interstitial dendritic cells of the heart harbor Trypanosoma cruzi antigens in experimentally infected dogs: importance for the pathogenesis of chagasic myocarditis. Am J Trop Med Hyg. 2000;63:64-70.

40. Cunha-Neto E, Duranti M, Gruber A, et al. Autoimmunity in Chagas disease cardiopathy: biological relevance of a cardiac myosin-specific epitope crossreactive to an immunodominant Trypanosoma cruzi antigen. Proc Natl Acad Sci U S A. 1995;92:3541-3545.

41. Burgos J, Begher S, Silva H, et al. Molecular identification of Trypanosoma cruzi tropism for central nervous system in Chagas reactivation due to AIDS. Am J Trop Med Hyg. 2008;78:294-297.

42. Vago A, Andrade L, Leite A, et al. Genetic characterization of Trypanosoma cruzi directly from tissues of patients with chronic Chagas disease: differential distribution of genetic types into diverse organs. Am J Pathol. 2000;156:1805-1809.

43. Marin-Neto J, Cunha-Neto E, Maciel B, et al. Pathogenesis of chronic Chagas heart disease. Circulation. 2007;115:1109-1123.

44. Zhang L, Tarleton R. Parasite persistence correlates with disease severity and localization in chronic Chagas disease. J Infect Dis. $1999 ; 180: 480-486$.
45. Schijman A, Vigliano C, Viotti R, et al. Trypanosoma cruzi DNA in cardiac lesions of Argentinean patients with end-stage chronic Chagas heart disease. Am J Trop Med Hyg. 2004;70:210-220.

46. Benvenuti L, Roggerio A, Freitas H, et al. Chronic American trypanosomiasis: parasite persistence in endomyocardial biopsies is associated with high-grade myocarditis. Ann Trop Med Parasitol. 2008;102:481-487.

47. Viotti R, Vigliano C, Armenti H, et al. Treatment of chronic Chagas disease with benznidazole: clinical and serologic evolution of patients with long-term follow-up. Am Heart J. 1994;127:151-162.

48. Rodriguez Coura J, de Castro S. A critical review on Chagas disease chemotherapy. Mem Inst Oswaldo Cruz. 2002;97:3-24.

49. Garcia S, Ramos C, Senra J, et al. Treatment with benznidazole during the chronic phase of experimental Chagas disease decreases cardiac alterations. Antimicrob Agents Chemother. 2005;49:1521-1528.

50. Muratore C, Baranchuk A. Current and emerging therapeutic options for the treatment of chronic chagasic cardiomyopathy. Vasc Health Risk Manag. 2010;6:593-601.

51. Viotti R, Vigliano C, Lococo B, et al. Long-term cardiac outcomes of treating chronic Chagas disease with benznidazole versus no treatment: a nonrandomized trial. Ann Intern Med. 2006;144:724-734.

52. Sosa-Estani S, Segura E. Etiological treatment in patients infected by Trypanosoma cruzi: experiences in Argentina. Curr Opin Infect Dis. 2006;19:583-587.

53. Viotti R, Vigliano C. Etiological treatment of chronic Chagas disease: neglected evidence by evidence-based medicine. Expert Rev Anti Infect Ther. 2007;5:717-726.

54. OPS-OMS. Tratamiento etiológico de la enfermedad de Chagas. Conclusiones de una consulta técnica. Río de Janeiro: Inst Oswaldo Cruz; 1998.

55. Marin-Neto J, Rassi A Jr, Morillo C, et al. Rationale and design of a randomized placebo-controlled trial assessing the effects of etiologic treatment in Chagas cardiomyopathy: the Benznidazole Evaluation For Interrupting Trypanosomiasis (BENEFIT). Am Heart J. 2008;156: 37-43.

56. Marin-Neto J, Rassi A Jr, Avezum A Jr, et al. Benefit trial: testing the hypothesis that trypanocidal therapy is beneficial for patients with chronic Chagas heart disease. Mem Inst Oswaldo Cruz. 2009;1:319-324.

57. Grippo V, Mahler E, Elias F, et al. The heavy chain variable segment gene repertoire in chronic Chagas heart disease. J Immunol. 2009;183: 8015-8025.

58. Cerisola J. Evolución serológica de pacientes con enfermedad de Chagas aguda tratados con Bay 2502. Bol Chil Parasitol. 1969;24:54-59.

59. Cançado R. Tratamiento etiológico do doença de Chagas pelo benznidazol. Capitulo 19. Libro Trypanosoma cruzi e doença de Chagas. Brener Z, Andrade Z, Barral-Neto M, editors. Río de Janeiro, Brazil: Guanabara Koogan; 2000:389-405.

60. Virreira M, Torrico F, Truyens C, et al. Comparison of polymerase chain reaction methods for reliable and easy detection of congenital Trypanosoma cruzi infection. Am J Trop Med Hyg. 2003;68:574-582.

61. Sánchez O, Mora M, Basombrio M. High prevalence of congenital Trypanosoma cruzi infection and clustering in Salta, Argentina. Pediatrics. 2005;115:668-672.

62. Russomando G, Almiron M, Candra N, et al. Implementation and evaluation of a locally sustainable system of prenatal screening that allows the detection of cases of congenital transmission of Chagas disease in endemic zone of Paraguay. Rev Soc Bras Med Trop. 2005;38:49-54.

63. WHO. Control of Chagas disease. WHO Technical Report Series N-905, Geneva, Switzerland: WHO; 2002.

64. Bustamante J, Bixby L, Tarleton R. Drug induced cure drives conversion to a stable and protective CD8+ T central memory response in chronic Chagas disease. Nat Med. 2008;14:542-550.

65. Duffy T, Bisio M, Altcheh J, et al. Accurate real-time PCR strategy for monitoring bloodstream parasites loads in Chagas disease patients. PLoS Negl Trop Dis. 2009;3:419-429.

66. Britto C. Usefulness of PCR-based assays to assess drug efficacy in Chagas disease chemotherapy: value and limitations. Mem Inst Oswaldo Cruz. 2009;104:122-135. 
67. Solari A, Muñoz S, Venegas J, et al. Characterization of Chilean, Bolivian and Argentinian Trypanosoma cruzi populations by restrictive endonuclease and isoenzime analysis. Exp Parasitol. 1992;75:187-195.

68. Andrade S, Magalhaes J, Pontes A. Evaluation of chemotherapy with benznidazole and nifurtimox in mice infected with Trypanosoma cruzi strains of different types. Bull World Health Organ. 1985;63: 721-726.
69. Filardi L, Brener Z. Susceptibility and natural resistance of Trypanosoma cruzi strains to drugs used clinically in Chagas disease. Trans $R$ Soc Trop Med Hyg. 1987;81:755-759.

70. Coronado X, Zulantay I, Rozas M, et al. Dissimilar distribution of Trypanosoma cruzi clones in humans alter chemotherapy with allopurinol and itraconazole. J Antimicrob Chemother. 2006;58:216-219.

\section{Publish your work in this journal}

Drug Design, Development and Therapy is an international, peerreviewed open-access journal that spans the spectrum of drug design and development through to clinical applications. Clinical outcomes, patient safety, and programs for the development and effective, safe, and sustained use of medicines are a feature of the journal, which has also been accepted for indexing on PubMed Central. The manuscript management system is completely online and includes a very quick and fair peer-review system, which is all easy to use. Visit http://www.dovepress.com/testimonials.php to read real quotes from published authors.

Submit your manuscript here: http://www.dovepress.com/drug-design-development-and-therapy-journal 